\title{
Semantic Web Technologies Applied to E-Learning System
}

\author{
Walid Qassim Qwaider, PhD. \\ Majmaah University \\ College of Science and Humanities in Ghat \\ Management Information Systems Dept. \\ Saudi Arabia
}

\begin{abstract}
The e-Learning community is aiming at having much more effective services than what is currently provided by any of the available computer aided tutoring, or learning management systems. The semantic web technology has the potentiality to be applied in different areas. E-Learning is one of the domains which may benefit from this new web technology. In this paper we design Semantic Web technology for realizing sophisticated learning scenarios. First we will see the potential uses of Semantic Web technology in e-Learning, overview of layers of the Semantic Web architecture and Metadata in e-Learning. We will see the advantages of using ontology to describe the learning materials. Also, a conceptual architecture of Semantic e-Learning portal is presented along with some related work.
\end{abstract}

\section{Keywords}

e-Learning, semantic web, Semantic Services for e-Learning, ontology, Metadata.

\section{INTRODUCTION}

The scene today is characterized in the field of technology enhanced learning by the large and growing number of providers of educational services is not homogeneous. For a user to need special education, a typical scenario involves a user visiting one or several educational centers on the Internet, and browse the offerings, and gather information about the courses (programs of study, and requirements, and tools needed, price, etc.), and choose the most of course is suitable for their needs preferences, Finally, the registration of that. This review is very manual and time-consuming, and usually, a user will visit only a very few centers on the Internet before making a decision [1].

It is clear that new methods of learning are some of the challenges ahead for each industry.

Learning is a critical support mechanism for organizations to enhance the skills of their employees, and thus the overall competitiveness in the new economy [2].

E-learning is the only time in education with high speed integrated value chains. It is delivered, a comprehensive individual dynamic content, and learning in real time, and assistance in the development of communities of knowledge, linking learners and working with experts [2].

E-learning is designed to replace the old time / place / content predetermined learning with only one at the right time /, in the workplace on demand / at the demand of the learning process. It is based on several pillars, viz. Management, culture and information technology (Maurer and engineers of mines 2001). E-learning has its origins in computer-based training (CBT), which was an attempt to automate education, replace the paid coach, and develop self-paced learning. But the focus in e-learning is to expand and improve the users and business needs. "The key to success is the ability to reduce the cycle time to learn and adapt to the" content and the size and style of "learning for the user of them, and their business environment [3]. Table 1 shows the characteristics of standard training and improvements achieved using e-learning approach [4].

Table 1: comparative between e-Learning and training [2]

\begin{tabular}{|l|l|l|}
\hline \multicolumn{1}{|c|}{ Dimensions } & \multicolumn{1}{|c|}{ E-Learning } & \multicolumn{1}{c|}{ Training } \\
\hline Delivery & Pull - Student determines agenda & Push - Instructor determines agenda \\
\hline Access & $\begin{array}{l}\text { Non-linear - Allows direct access to knowledge } \\
\text { in whatever sequence makes sense to the } \\
\text { situation at hand. }\end{array}$ & $\begin{array}{l}\text { Linear - Has defined progression of } \\
\text { Knowledge. }\end{array}$ \\
\hline Responsiveness & $\begin{array}{l}\text { Reactionary - Responds to problem at } \\
\text { hand }\end{array}$ & $\begin{array}{l}\text { Anticipatory - Assumes to know the } \\
\text { problem }\end{array}$ \\
\hline Modality & $\begin{array}{l}\text { Continuous - Learning runs in the parallel to } \\
\text { business tasks and never stops. }\end{array}$ & $\begin{array}{l}\text { Discrete - Training takes place in } \\
\text { dedicated } \\
\text { Chunks with defined starts and stops. }\end{array}$ \\
\hline Symmetry & $\begin{array}{l}\text { Symmetric - Learning occurs as an integrated } \\
\text { activity. }\end{array}$ & $\begin{array}{l}\text { Asymmetric - Training occurs as a } \\
\text { separate } \\
\text { Activity. }\end{array}$ \\
\hline Personalization & $\begin{array}{l}\text { Personalized - Content is determined by the } \\
\text { individual user's needs and aims to satisfy the } \\
\text { needs of every user. }\end{array}$ & $\begin{array}{l}\text { Mass produced - Content must satisfy the } \\
\text { Needs of many. }\end{array}$ \\
\hline Modality & $\begin{array}{l}\text { Continuous - Learning runs in the parallel to } \\
\text { business tasks and never stops. }\end{array}$ & $\begin{array}{l}\text { Discrete - Training takes place in } \\
\text { dedicated chunks with defined starts and } \\
\text { stops. }\end{array}$ \\
\hline
\end{tabular}




\begin{tabular}{|l|l|l|}
\hline Adaptively & $\begin{array}{l}\text { Dynamic - Content changes constantly through } \\
\text { user input, experiences, new practices, business } \\
\text { rules and heuristics }\end{array}$ & $\begin{array}{l}\text { Static-Content and } \\
\text { organization/taxonomy } \\
\text { Remains in their originally authored form } \\
\text { without regard to environmental changes. }\end{array}$ \\
\hline Authority & $\begin{array}{l}\text { Distributed - Content comes from the interaction } \\
\text { of the participants and the educators. }\end{array}$ & $\begin{array}{l}\text { Centralized - Content is selected from a } \\
\text { library of materials developed by the } \\
\text { educator. }\end{array}$ \\
\hline
\end{tabular}

The techniques of improving education in all the time and always used new technologies first through education, especially with the emerging computer technology related information. Education Network (including distance education, distance learning), or e-learning with the growth of computer networks. Has resulted in wireless and mobile computing in education or mobile learning [5].

With wireless technologies and mobile phones, and it is possible to achieve anytime, anywhere, in any case, any device for learning and teaching. Implementation of $\mathrm{m}$ learning involves the addition of mobile computing technologies in the education system old email. Modify the legacy systems need a lot of work: Engineering re-design and re-implementation of the monitoring system of education. In the meantime, a large number of universities update their systems, and will be ported many more educational resources for new systems [2].

This paper shed light on the effective use of Semantic Web technology to achieve advanced learning scenarios. First we will see potential uses of Semantic Web technology in the overview, e-learning from the layers of the architecture and the Semantic Web metadata in e-learning. We will see the advantages of using ontology to describe the educational materials. Also, provide a conceptual structure of semantic elearning portal along with some related work.

\section{BACKGROUND AND RELATED WORK}

Our work deals with some of the concerns recently expressed by others such as [5]. It is noted that there are several challenges in improving education on the Internet, such as providing more adaptive and intelligence, and this is an essential component of this improvement will be the provision of support and Judy. structures from distributed metadata. It is based primarily on ontology-based descriptions of the context, content and structure of educational materials, and thus provides access flexible and personal nature of these educational materials [3].

Dutta, and focuses on the potential uses of Semantic Web technologies in e-learning, and the advantages of using ontology to describe the educational materials. Is also provided a conceptual structure of e-Learning Portal privately with some related work [1].

Alsultanny, design e-learning system through the use of semantic web, and show how they can benefit from the resources forms on the web to generate a semantic description of automatic hypertext

Yale, present the main features of our learning organizational memory and we focus on the ontologies on which it is based. We consider two kinds of ontologies: the first one is generic and concerns the domain of training; the second one is related to the application domain and is specific to a particular training program. We present our approach for building these ontologies and we show how they can be merged. Finally we describe the learning memory and the prototype we realized for two course units proposed in our universities [7].

Rokou, presented three basic levels in each application on the Internet: e character of the program, the educational background, personality and management of educational materials. Identified in the program on the Internet as a system of information that contains a Web server, network, communications protocol such as HTTP, and browser that the data provided to users to work on the system and cause changes. Educational background means the educational model that is used in combination with the educational goals set by the coach. Personal management of learning materials means a set of rules and mechanisms that are used to determine the educational materials on the basis of student characteristics, educational goals, and the model of teaching, and media available [6].

The hierarchical contents structure is able to show the entire educational contents, the available sequence of learning, and the structure of the educational concepts, such as the related super- or sub- concepts in the learning contents. Furthermore, some of semantic relationships among the educational contents, such as 'equivalent', 'inverse', 'similar', 'aggregate' and 'classified', can provide important and useful information for the intelligent elearning system [8].

\section{CHARACTERISTICS OF E- LEARNING SYSTEM}

Can describe the process of traditional learning as our central authority (is determined by content by the teacher), delivered a boost (science teacher a boost to the students), and lack of personalization (content must meet the needs of many), and the process of learning static / linear (unchanged content) . However, it should be a learning process - fast and just in time (cheap), and relevant (which depends on the problem), which is possible with the distributed, student-oriented, personal, and the process of learning non-linear/dynamic - what is possible in the e-learning [1]. Important characteristics of e-learning are:

- Pull- student determines agenda.

- Interactive- responds to problem at hand.

- Non-linear- allow direct access to knowledge in whatever sequence make sense to the situation at hand.

- Systematic- learning occurs as in integrated activity.

- Continuous- learning runs in the parallel loops and never stops.

- Distributed- content comes from the interaction of the participants and the educators.

- Personalized- content is determined by the individual user's needs and aims to satisfy the needs of every user.

- Dynamic- content changes constantly through user input, experiences, new practices, business rules and heuristics.

Out of e-learning is computer-based training (CBT), which was an attempt to automate education, replace the paid coach and develop self-paced learning. The aim of e-learning is not only the registered education (as in CBT), but also education 
without barriers of time and distance, and designed specifically for users and business needs [1].

\section{LAYERS OF THE SEMANTIC WEB TECHNOLOGEIS}

Expressing the meaning of "is the main task of the Semantic Web. In order to achieve this there is a need to target several layers of representative structures. And progress these amendments in Figure 1, including the following layers are the basic ones:

- XML layer, which represents the structure of data.

- RDF layer, which represents the meaning of data.

- Ontology layer, which represents the formal common agreement about meaning of data.

- Logic layer, which enables intelligent reasoning with meaningful data.

Upon semantic aims to reach out to distributed data and services related to the specific and in such a way that can be used by devices not only for display purposes, but for integration, automation and reuse of data and services across various applications [9]. And described some of the functions of the Semantic Web as follows:

- Automatic discovery of Web service: automatically find the location of the Web services that provide a particular function.

- Automatic Web service invoked: involves the implementation of automatic Web service that have been identified. Automatic control of a Web service: helps users know the status of officials or the Web service when it is invoked.

- Automatic Web service composition: a mechanism involving the formation and interoperation of Web services to perform some tasks. With this function, can be made up some new activities automatically without the need for programming.

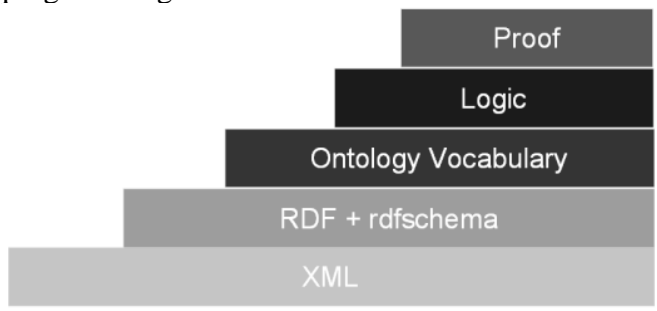

Fig 1: Layers of the Semantic Web Architecture [20].

Founded semantics of resources, which have been identified by a unique identifier of the resource (URI) or internationalized resource identifier (IRI). The next layer semantic is XML, a set of rules syntax for "create markup languages rich language in a particular area" with spaces (the "simple mechanism to create unique names on the global level to elements and attributes of the markup language", to avoid conflicts vocabulary) [10 ]. On top of XML is a framework that describes resources, RDF, simply, the language of XML to describe the full resources (as opposed to just parts of them, as is the case with XML). RDF schema is the language that enables the creation of vocabulary of RDF, RDF Schema is based on object-oriented approach [11].

\section{E-LEARNING AND SEMANTIC WEB TECHNOLOGEIS}

$\mathrm{Ah}$ the great achievements of the current global communication network leads to a new challenge: a huge amount of data for interpretation by humans only, and only support the device. Berners-Lee suggests to enrich the site by the device is able to process information, which supports the user in his tasks. For example, today's search engines are already very strong, but the return is still often very large lists or insufficient effectiveness. Machine can process information indicates that the engine is able to search on the relevant pages, and can thus improve both the precision and recall. Will be to reach this goal can not even build a network of meanings in different levels: resource identifiers Unicode / standard, XML, RDF, literature, logic, and the proof, and trust [3].

E-learning is one of the areas that can benefit from Semantic Web technologies. This technology has enabled the Semantic Web by a group of appropriate factors, which appear to be strong enough to meet the requirements of e-learning - a quick, fair, timely and relevant learning [1]. The potential uses of Semantic Web technology for e-learning is [12]:

- Cloud: The distribution of elements of knowledge (educational materials) on the Internet, but are linked to an agreed ontology (s). This path can be built for the user, through semantic query topics of interest.

- Interactive: Software Agents on the Semantic Web may use agreed language, which enables the coordination between the agents and proactive delivery of educational materials in the context of actual problems. This vision is that each user has a personal agent that communicates with other factors.

- Non-linear: the user can describe the situation at hand (the objective of learning and prior knowledge, ...) and perform the query on the meanings of appropriate educational materials. Also calculated for the user profile. Can be expanded access to knowledge navigation through specific language.

- Symmetric: the Semantic Web (semantic intranet) offers the ability to become the integration platform for all business processes in the organization, including the learning activities.

- Continuous: Active delivery of information (based on personal factors) creates a dynamic learning environment.

- Distributor: Semantic Web will be centralized as much as possible. This allows for effective collaborative content management

- Personal: The user can (using a personal factor) the search for educational materials and customized to their needs him /. Ontology is the link between user needs and characteristics of educational materials.

- Dynamic: the Semantic Web enables the use of knowledge available in various forms, through the linguistic explanation of the content. Distributed nature of the Semantic Web enables continuous improvement of learning materials.

\section{ONTOLOGIES FOR E-LEARING SYSTEM}

The ontology term used widely in recent years in the field of intelligence, and computer and information industry, especially in areas such as, information systems, cooperative, intelligent information integration, and information retrieval and extraction, knowledge representation, and database 
management systems. And suggests many different definitions of the term. One of the most quoted definition is widely known and ontology is Gruber [13], ontology is a specification of the concept of a clear [14].

It can also ontologies that are used to support the specification services logic, thus allowing not only 'fixed' joint action through the perceptions of the scope of joint, but also "dynamic" work together through the dissemination of clear standards of efficiency, which can all cause to determine the semantic private Web service is suitable for a particular task [15].

Ontologies can be used in blended e-learning (on-line and face-to-face interaction) as a means to describe the formal organization of universities and training courses and to identify services. Must be on the ontology of e-learning, including a description of educational institutions (providers of course), and courses, and the people involved in the process of teaching and learning. Some suggestions are without the use of the footage that was created using WebOnto [16].

\section{METADATA}

System metadata is structured information that describes resources, which was established to assist in the mission to discover, manage, and use it without having to be read, seen or explored one way or another. Metadata is the sum total of what one can say about any information object at any level of aggregation, given that the object information is something that can not be processed and manipulated by a human or the system as a separate entity. Search metadata to enable effective use of resources across multiple warehouses, since dealing with agents and descriptive of the resources is easier than dealing with the resources themselves. It can facilitate the use of a particular object by different communities through the presence of metadata records that describe the different schemes according to the metadata according to the needs of each community [3].

\section{METADATA AND E-LEARNING SYSTEM}

Here we offer the outline of the metadata used to create elearning system. Home EN-points is to try to enter the system, and the approach course, the approach to teaching, and assessment of learning, and communication between students and lecturers and learners and learners, and help system, and enhance the information and news, and other facilities for teachers and students. Known as metadata management system for e-learning and formal description of the process of managing e-learning. We use ontology to build a rich description of each step in the management process, as well as objects to serve the educational Semantic Web. Lytras, Sicily, [17] indicate a similar approach used for modeling objects of learning information systems. This approach includes the selection, installation, integration and assessment of learning objects, as well as an assessment of needs and gaps, and learning activities [14].

\section{SEMANTIC WEB PORTAL CONCEPTUAL E-LEARNING PORTAL ARCHITECTURE.}

System architecture is represented in the figure. 2. Repository of knowledge as a metadata repository, and the intermediary system is a mechanism inferred Home. Basic units, such as the shape. 1 shows the conceptual architecture of semantic elearning portal, which provides the highest level of services for people who are looking for online courses appropriate, consistent with the core activities in e-learning environment [1]:

The access interface: It provides an integrated interface through which readers, as well as writers / directors of academic institutions can access, download or modify data with special authority.

Services: provides various services, such as, inspections of personal service and notice, a footnote, of course, etc..

Knowledge base: This is the basic element and the essence of architecture. It is a warehouse where ontologies, metadata, and rules of inference, and learning resources and course descriptions, user profiles are stored. The metadata can be placed within the same document or in some external repository metadata (such as warehouse RDF) (14). Here the data is stored externally in a descriptive knowledge base. Benefits of external storage are: (i) it is easier to clear a separate description of metadata stored in a database and takes less space to store it, and (II) and the point of view may vary according to different authors to re-use the same materials. Which means that it is possible to have different descriptions of educational materials and according to different contexts [18].

Search Engine: This provides the Institute with the methods of querying the knowledge base. Can RDQL (RDF Data Query Language) is used as the language of ontology query.

Inference engine: from answering questions, and is responsible for the conclusion of new realities through the intelligent combination of facts already have in their knowledge base. 


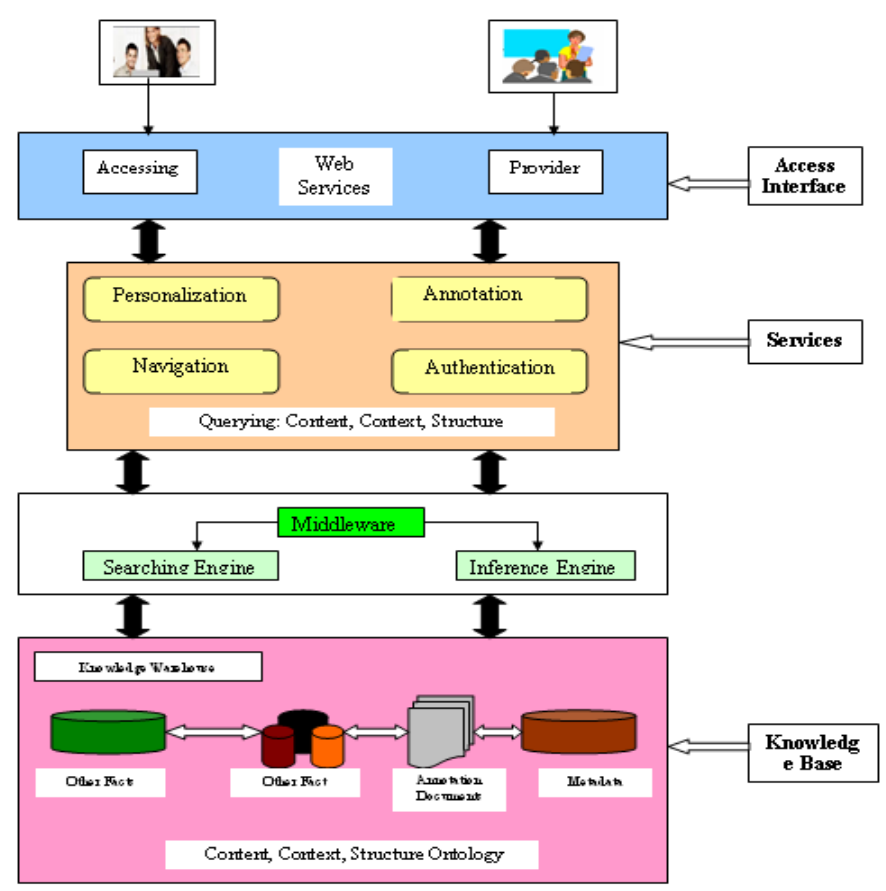

Fig 2: Semantic e-Learning Portal Architecture

The main activities in e-learning environment and provide information of the book, and access to educational materials by readers and writers through the query and browsing through.

\section{CONCLUSION}

Content, which makes the machine is to re-formulate the concept of the popularity of the basic conditions for the Semantic Web. Semantic Web is an emerging technology aimed at web-based information and services that would be understandable and usable by both humans and machines. In this paper is the architecture we have outlined a Semantic Web services technology in the context of e-learning portal, and a description of the various scenarios within this architecture, including enrollment in the course of the article demanded. We have used ontologies to describe the learning materials, diagrams and explain the ontology of services.

Structure moves away from the traditional teacher and student in the teacher that determines the educational materials that will be absorbed by the students and about again, and the structure more flexible in learning where students take responsibility for their own learning, and determine the agenda of learning, including what is to be included and. In the presence of what is otherwise more options, students also have greater access to semantic technologies.

The purpose of this paper to illustrate the possibilities of using the Semantic Web as the backbone of e-learning. In the first place, the objectives are to facilitate the effective contribution and access to information. But, in general, the process of Semantic Web-based education to be relevant (which depends on the problem), a personal (assigned by the user) and active (context-sensitive) process. This is the prerequisite for effective learning [19]. This new view enables us to go a step further, consider or explain the process of learning as a process of knowledge management in the right place, at the appropriate time, properly in order to meet business objectives.

\section{REFERENCES}

[1] Dutta, B. Semantic Web Based E-learning. (2006). Semantic Web Based E-learning. DRTC Conference on, ICT for Digital Learning Environment, 11th $-13^{\text {th }}$ January, 2006, DRTC, Bangalore.

[2] Drucker, P. (2005), "Need to Know: Integrating eLearning with High Velocity Value Chains", A Delphi Group White Paper.

[3] Alsultanny Y, (2006) “e-Learning System Overview based on Semantic Web" The Electronic Journal of e-Learning Volume 4 Issue 2, pp 111 - 118, available online at www.ejel.org.

[4] Barker, Ph. (2000),"Designing Teaching Webs: Advantages, Problems and Pitfalls. Educational Multimedia, Hypermedia and Telecommunication, Association for the Advancement of Computing in Education", pp. 54-59.

[5] Devedzic, V. (2004). Education and the Semantic Web. In International Journal of Artificial Intelligence in Education 14 (2004) 39-65. IOS Press.

[6] Rokou. F. P. et al. ( 2004). "Modeling web-based educational systems: process design teaching model," Educational Technology and Society, Vol. 7, pp. 42-50.

[7] Abel, M.-H., Benayache, A., Lenne, D., Moulin, C., Barry, C., \& Chaput, B. (2004). Ontology-based Organizational Memory for e-learning. Educational Technology \& Society, 7 (4), 98-111.

[8] Ghaleb. F, Daoud S, Hasna A, Jaam.et al. (2006).ELearning Model Based On Semantic Web Technology. International Journal of Computing \& Information Sciences, Pages $63-71$. 
[9] Guangzuo, C, Fei. C, Hu. C, Shufang. Li," OntoEdu: A Case Study of Ontology-based Education Grid System for E-Learning", Modern Education Technology Center at Peking University 100871, 2005.

[10] Daconta, M. C, Obrst, L. J., \& Smith K. T. (2003). The Semantic Web: A Guide to the Future of XML, Web Services, and Knowledge Management, New York: Wiley.

[11] Cristea, A. I. (2004). What can the Semantic Web do for Adaptive Educational Hypermedia? Educational Technology \& Society, 7 (4), 40-58.

[12] Stojanovic. L, Staab . S, Studer. R.( 2001). E-Learning based on the Semantic Web. IST, 28293,.

[13] Gruber, T. R. (1993). A translation approach to portable ontology specification. Knowledge Acquisition, 5(2), 199-220.

[14] Snae. C \& Brueckner. M," Ontology-Driven E-Learning System Based on Roles and Activities for Thai Learning Environment", Interdisciplinary Journal of Knowledge and Learning Objects, Volume 3, 2007.

[15] McIlraith, S., Son, T. C., \& Zeng, H. (2001) Semantic Web Services, IEEE Intelligent Systems, 16 (2), 46-53.
Moreale, E., \& Vargas-Vera, M. (2004). A QuestionAnswering System Using Argumentation. Lecture Notes in Computer Science, 2972, 400-409.

[16] Domingue, J. (1998). Tadzebao and WebOnto Discussing, Browsing, and Editing Ontologies on the Web. Paper presented at the 11th Knowledge Acquisition for Knowledge-Based Systems Workshop, 18-23 April, Banff, Alberta, Canada.

[17] Lytras, M. D., \& Sicilia, M.-A. (2005). Modeling the organizational aspects of learning objects in Semantic Web approaches to information systems. Interdisciplinary Journal of Knowledge and Learning Ob-jects, 1, 255-267. Available at

[18] Santos, Juan M., Anido, Luis and Llamas, Martin. Design of a Semantic Web-based Brokerage Architecture for the E-learning Domain. A Proposal for a Suitable Ontology, 2005.

[19] Stojanovic, Ljiljana, Staab, Steffen and Studer, Rudi. eLearning based on the Semantic Web,2002.

[20] BERNERS-LEE T. Semantic We- XML2000. W3C Website 2000. URL: http://www.w3.org/2000/ Talks/1206-xml2k-tbl/ slide10-0.html. 